This is an Open Access article distributed under the terms of the Creative Commons Attribution 4.0 International License which permits unrestricted non-commercial use, distribution, and reproduction in any medium provided the original work is properly cited

\title{
ANALYSIS OF THE IMPLEMENTATION OF NURSING PROFESSIONAL VALUES IN REFERRAL HOSPITALS JAKARTA: FISHBONE ANALYSIS
}

\author{
Rutmauli Hutagaol ${ }^{1}$, Hanny Handiyani ${ }^{2}$, Nurdiana ${ }^{3}$ \\ 1 Postgraduate Student, Faculty of Nursing, Universitas Indonesia \\ 2 Department of Basic Science \& Fundamental Nursing, Universitas Indonesia \\ 3 Cipto Mangunkusumo Hospital \\ * Correspondence: rutmauli.ht.gaol@gmail.com
}

\begin{abstract}
Professional values can direct nurse behavior. Nurse behavior should reflect caring in providing nursing services as the essence of nursing. The study aimed at analyzing the implementation of nursing professional values. The method used in this paper is a case study. Data collection is done by interviews, document observation, and distributing questionnaires to nurses in the amount of 517 nurses. The questionnaire used was the Nursing Professional Value Scale and Nurse that was modified and used to determine the nurse's professional score scale. Interviews were conducted with the field and nursing committee using a semi-structured interview guide. Interview material includes management functions related to the application of the nurse's professional values. Data analysis using fishbone analysis. The results showed that the professional score scale of nurses was quite strong, namely 101.19, but the application of professional nurses' values was still not optimal because some nursing leaders were still less professional. The recommendation from this case study is that nursing management needs to motivate nurses to apply nurses' professional values through attitudes and behaviors that have implications for the quality of nursing services and have an impact on patient satisfaction and safety.
\end{abstract}

Keywords: Fishbone analysis, management of service, nurse professional values

\section{Introduction}

Professional value serves as a compass for nurses to be able to display the expected behavior of nurses as health care providers. Professional values can direct nurse behavior. Values represent fundamental beliefs about what is right, proper, or desired, and motivates social and professional practice (1). Professional values function as a standard of behavior accepted by practitioners and professional groups recognized in their profession (2). (3) Proves that there is a strong relationship between professional values and nurses' work motivation. Professional value builds a strong 
foundation for the future of nurses that provide the basis for ethical, value-based and humanistic care (4). Therefore, professional values are essential for the future of nursing.

Professional caregivers (PC) are required to be able to serve the community well and professionally, both at the Puskesmas level and to the hospital. Nurses as part of the PC contained in (5) are required to be professional and competent in providing nursing services. The public view perceives that a nurse is said to be licensed if the nurse has ethical behavior and caring in providing services. Becoming a PC does not only require competence in providing nursing services, but it needs attitudes and behaviors that reflect ethics and caring.

The application of professional values possessed by Indonesian nurses is still mostly not optimal according to the perspective of society. This can be seen from the stigma of the people who still think that nurses are bitchy, fussy, and rarely smile. Research conducted by (6) as obtained by $58 \%$ of patients stating dissatisfaction with nursing services in a hospital. Different research conducted by (7) gathered data from in-depth interviews that patients were disappointed in nursing services including the attitudes and behavior of nurses. The application of nurses' professional values can be seen through the attitudes and behavior of nurses in a professional manner which ultimately gets a response from patients as service recipients.

Professional nurses are related to patient safety. Professional nurses result in increased patient care and greater job satisfaction for nurses, increasing client recognition and nurse retention (4). Research conducted by (8) proves that professional nurses placed in acute care areas can reduce the risk of death of patients. (9) State that professional nurses can help improve the quality of nursing care. This proves that if a licensed nurse will have an impact on the quality of care and improve patient safety.

The care provided by nurses is based on standard practice. In Australia, (10) has made professional practice standards for nurses into two categories namely professional practice standards and performance standards. Practice Standards describe the level of competency of nursing care as a model of critical thinking known as the nursing process, while professional performance standards describe the level of behavioral skills related to ethics, culture-based practices, communication, collaboration, leadership, education, training, and evidence-based research. In Indonesia, as contained in (11) states that nursing practice is held in the form of nursing care. Nurses in carrying out nursing care have two elements, namely the aspect of competence and behavior (12). Standards are useful for guiding the appearance of nurses in meeting the demands of patient expectations to give satisfaction to patients.

Patient satisfaction at one of the public hospitals in Jakarta where researchers conduct residency practices including good categories. Data is obtained that the patient satisfaction rate in the period January-September 2018 can meet the set target of $85.28 \%$, while the expected goal is $85 \%$. Performance indicators of service quality are also fulfilled from the period June-October 2018. Interviews with several patients and families of patients in one of the outpatient units at the hospital said they were satisfied with the services provided by nurses. This is an exciting thing to study regarding professional values that direct the professional behavior of nurses that have an impact on the quality of nursing services, patient safety, and patient-centered services. 


\section{Objectives}

This study aimed at analyzing the application of nurses' professional values using a fishbone model

\section{Method}

The method used is in the form of case studies and analysis of results and gaps with discussion based on literature review and expert debate. Data retrieval is done through interviews, field observations, and distributing questionnaires to determine the nurse's professional value scale. The questionnaire was given to nurses as many as 517 nurses in a referral hospital in Jakarta.

The questionnaire used was a modified Nursing Professional Value Scale and Nurse. The questionnaire was used to obtain the results of the nurse's professional score scale. Interviews about the roles and functions of fields and nursing committees related to the implementation of professional values of nursing staff were obtained through semi-structured interview guides.

The interview material asked to the field and the nursing committee regarding nursing management functions which consisted of planning, organizing, staffing, directing, and controlling. The observation method is carried out to identify the availability of supporting documents in the clinic. Data obtained from observations and interviews were grouped and analyzed. Data analysis using fishbone analysis by describing the gap found. This study is an innovation legalized to collect data and publish the research result conducted in the hospital where the researcher did this study.

\section{Result}

\subsection{Interview}

Interviews found that professional values were applied by the guidelines for staff behavior and nursing bylaw staff which served to regulate and direct nurses' behavior to be as expected by the organization of the organization. Bylaw's behavioral and nursing staff guidelines were socialized to all new nurses and nurses during the admissions process. This is done so that new nurses have the same values as those adopted by the hospital. While the old nurses were given a reeducation through a road show to all the rooms so that the professional values were also embedded in old nurses. Training related to the formation of professional values of nurses has been carried out. The training provided was service excellence in 2016 which included values and culture material adopted at the hospital.

Provision of remuneration is made to motivate nursing staff to behave according to the professional values of the team. The value of the compensation is adjusted to the results of the assessment of the head of the room. The hospital also imposes sanctions on staff when committing a violation. The sanctions given are adjusted to PP 53 of 2010 concerning the discipline of civil servants. The nursing committee motivates peer groups or head of rooms to become role models for nursing staff. But in its 
implementation, there are still some nursing leaders who cannot implement according to the policies that have been made. This is probably due to inadequate supervision from the leadership.

\subsection{Observation}

Nurse behavior guidelines are made in the form of a pocketbook so that nurses can carry easily to read and each nurse has been given. Bylaw Nursing staff has also been socialized to each new nurse at the time of the recipient in the nursing field so that the new nurse understands how professional behavior is expected and by the policy in the hospital.

\subsection{Questionnaire}

The results of the questionnaire found that the average score of professional nurses was quite strong $(101,19)$. The knowledge of nursing staff regarding the professional values adopted at the hospital has also been excellent. This is evidenced by the questionnaire that $72.10 \%$ of nurses know the value of professionals in the hospital. The highest professional value averaged 40.93 perceived by nurses is trust, then followed by caring (30.45) and professionals (29.81).

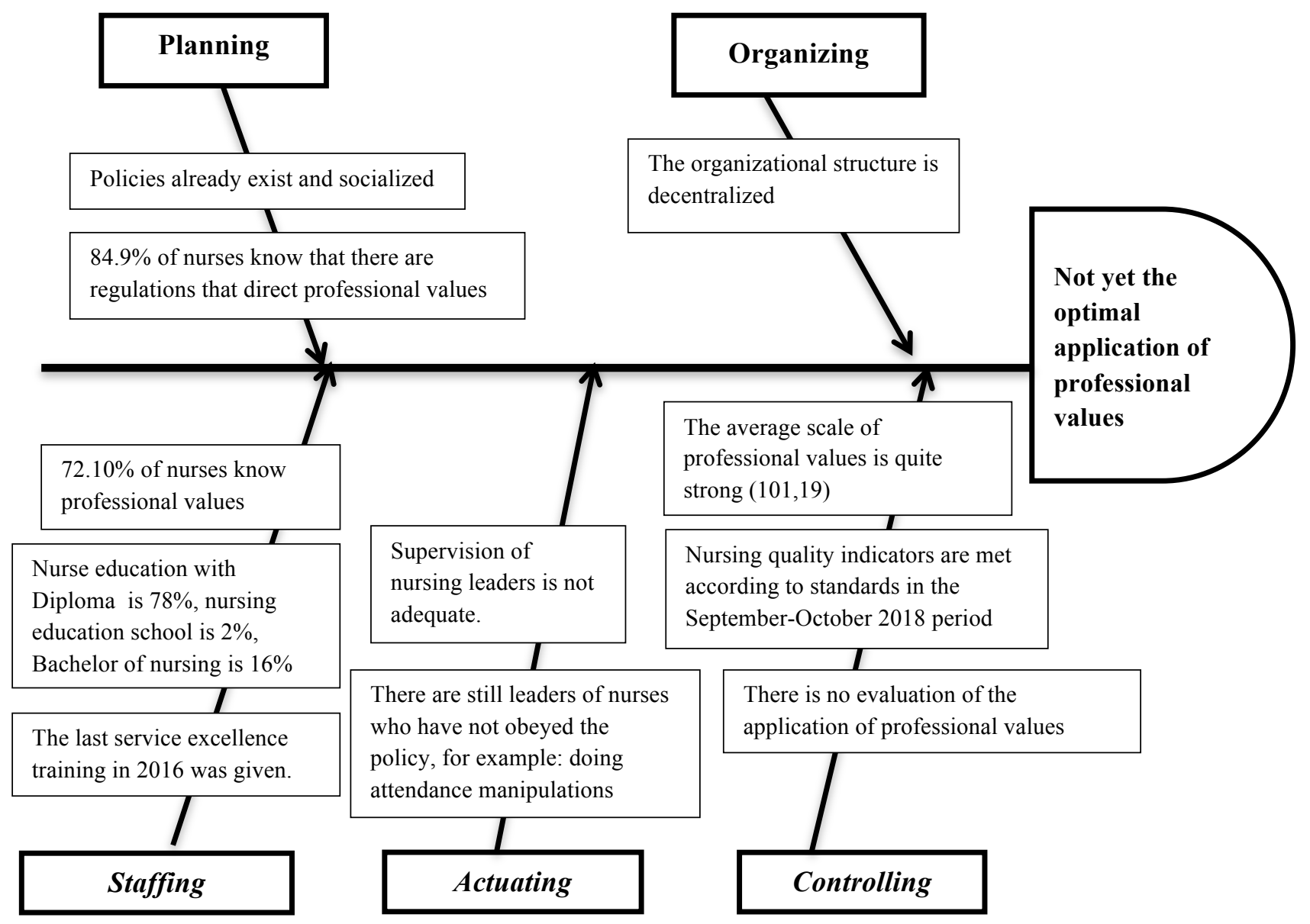

Figure 1. Fishbone Diagram 


\section{Discussion}

Based on the Nursing and Midwifery Board of Australia (10) that the code of conduct is useful as a standard for directing nurses' behavior to be by the law and able to apply professional behavior in all nursing practice services. The arrangement of nursing practice includes collaborative relationships between nurses and patients, and other health teams, and management so that nurses can work together to provide the best service. In line with NMBA, Nursing and Midwifery Board of Ireland (13) states that standards aim to guide nurses in practice and help nurses understand professional responsibility in caring for patients in a safe, ethical and effective manner. Standards guide to directing nurses' professional behavior.

The behavior of nurses as PC have an impact on patient satisfaction. Nurses' competencies and behavior are important in providing quality nursing care (14). Previous studies reported that patients are satisfied with the services of nurses in hospitals in Malaysia because of nurse behavior that shows respect, smile, and caring. Research conducted by $(15,16)$ to explore caring behavior of nurses in hospitals in America perceived by patients with intubation and their families is to provide information, be competent, attend, provide guidance, and use a soothing tone of voice. A nurse's professionalism will be seen through the attitudes and actions displayed in providing nursing care.

Nurses' behavior in providing nursing care is supported by the effectiveness and efficiency of the workforce. On the other hand, the proportion of nurse resources that is balanced with workload also helps the quality of nursing care to achieve optimal results. Taher (2014) made the proportion of nurses based on education levels in health facilities such as hospitals associated with nurses with Ners, and Vocational graduates were $60 \%$ and $40 \%$. Many are found in several nurse hospitals working for 12 hours per shift or 60 hours per week. At the end, which causes physical, cognitive, and emotional nurse problems, which can be thought of in the quality of nursing care services (Kennedy, 2016). The critical thinking competencies needed by nurses with nurse training will undoubtedly be better than vocational nurses who are adjusted to the curriculum at the time of education. Therefore, a strategic and systematic staffing plan is needed in meeting professional nurse resources.

Professional nurses are required to be able to be role models or role models for patients as well as fellow nurses. Role models become one of the roles of nursing managers (17). (10) Say that nurses have professional roles and responsibilities to obtain, maintain knowledge and skills possessed to be able to become role models. (18) And (19) study showed that nurse leadership behavioral characteristics and interpersonal work relationships had a relationship with patient safety, increased health costs, and nurse morale. Nursing managers become role models for their staff so that nursing managers should set a good example through their attitudes and behavior.

There are many things that nursing leaders can do to become role models. Nurse role models not only include attitudes in providing nursing services, acting and appearing, but role models in communication are equally important (17). Communication is an integral part of patient care and is one of the factors that determine the quality of care (20). Nurses' attributes as role models are caring, nonjudgmental, trustworthy, inspiring and motivating, knowledgeable and confident, innovative, and professional (21). 
The results of the professional score scale scores of nurses can determine how strong nurses hold professional values. The scale of professional scores of nurses at the hospital where the study was conducted was quite strong, namely 101.19. The results obtained were not much different from the average score of professional nurses in Korea, namely 101.86 (22). This is far different from the professional scale of nurses in Turkey with an average score of professional scores of 165.41 (23). The results of this professional value scale are categorized as very strong. The difference in scores is caused by cultural differences (24). Culture contains a set of values, beliefs, and habits learned throughout life that shapes individual behavior. The professional score of the nurse will be felt if professional values are applied to behavior.

The application of professional values in the form of nursing services can be seen as one of them through the use of caring. Caring is defined as the core of nurses' professional values (25). (26) Has the opinion that caring is the essence of nursing and is inherent in the nursing profession, where caring is the basis in the unity of universal human values. Caring is also seen as the basis of the nursing profession which provides a framework for guiding nursing practice. Caring is also an essential component in increasing patient satisfaction in the health care environment. Caring will be seen through the behavior displayed by nurses in providing nursing care.

Caring is a universal phenomenon that affects the way humans think, feel, and have relationships with others. Caring is an action that shows the use of the patient's environment in helping to heal (Florence Nightingale in Alligood (2014). (26), Caring is a moral commitment to protect, maintain and enhance human dignity Caring as a primary form of nursing practice where nurses help clients recovering from his illness, giving an explanation of the client's disease, and managing or rebuilding the relationship Caring helps the nurse recognize right interventions, and then becomes the nurse should show a concern and instructions for giving caring Caring through her behavior as the essence of nursing.

Professional value is what is needed to direct the professional behavior of the nursing staff. The profound relationship between nurses and patients and families, affection, empathy, comfort, and care given in patient care is part of the attitude and behavior of nurses to patients (27). Another opinion expressed by Notoatmodjo (2012) is that belief is a psychological factor in shaping behavior while values represent the fundamental beliefs to direct one's behavior (17). The Florance Nightingale supported this in the 19th century that nursing should not only include scientific knowledge and technical skills but must become a profession that has professional values (28). (12) States that the application of professional values in nursing practice can help improve the quality of nursing care. This proves that professional value is one of the elements that must be possessed by a nurse.

The success of applying professional values in nursing is not easy. According to (29), several factors that influence nurses' professional values are membership status in nursing organizations, staffing status, nurse position, nurse work area. Different research conducted by Cheng, Meng, \& Jin (2015) that there is a relationship between burnout and professional values of nurses. This states that the work environment also affects one's professional value. Professional values are influenced by personal and social values and are modified and expanded through educational, clinical and personal experience (24). To support the application of professional values, nurses need to know the factors that influence it. 
Professional behavior can be sought by fostering value and confidence in nurses. To realize this, nurses are required to have a strong scientific foundation, good psychomotor abilities and professional attitudes in providing nursing care to patients so that professional nursing can be realized. Value and confidence in the profession will give birth to personal commitments from nurses. The personal responsibility of nurses is intended to display the values of nursing professionals who always contribute to advancing the profession and continuously strive for the best quality and best nursing services for patients (30).

\section{Conclusions and recommendations}

The results of the average professional score scale of nurses are said to be quite strong. Of the twenty-six items of questions categorized into three professional values of nurses. The highest results in professional values are trusts while the lowest is professional. The application of all professional values still lacks especially by nursing leaders. The recommendation from this case study is that nursing management needs to make regulations as a standard for increasing professional nurses especially in nursing leaders as role models that reflect the professional values of nurses that have an impact on the quality of nursing services.

\section{References}

1. Potter P, Perry A. Fundamental of nursing. 7th ed. America; 2009.

2. Weis D, Schank MJ. Professional values: the key to professional development. Journal of Professional Nursing. 2002;18(5).

3. Magdalena S. MStudy on the Motivational Variables and Professional Values in the Romanian. 2015;

4. Kaya H, Işik B, Şenyuva E, Kaya N. Personal and professional values held by baccalaureate nursing students. Nurs Ethics. 2017;24(6):716-31.

5. Undang-Undang Republik Indonesia Nomor 36 Tahun 2009 Tentang Tenaga Kesehatan. 2009;

6. Lu M, Ruan H, Xing W, Hu Y. Nurse burnout in China: A questionnaire survey on staffing, job satisfaction, and quality of care. J Nurs Manag. 2015;23(4):440-7.

7. Amalia A, Malini H, Yulia S. Kepuasan Perawat Terhadap Kualitas Pendokumentasian Asuhan Keperawatan Berbasis Komputer. J Keperawatan Indones [Internet]. 2018;21(3):169. Available from: http://jki.ui.ac.id/index.php/jki/article/view/680

8. Muhidin. Persepsi Pasien Terhadap Pelayanan Keperawatan Di Rumah Sakit Umum Daerah Sogaten Kota Madiun Jawa Timur. Universitas Indonesia; 2008.

9. Coster S, Watkins M, Norman IJ. What is the impact of professional nursing on patients' outcomes globally? An overview of research evidence. Int J Nurs Stud [Internet]. 2018;78(October 2017):76-83. Available from: https://doi.org/10.1016/j.ijnurstu.2017.10.009

10. Based on the Nursing and Midwifery Board of Australia: https:www.nursingmidwiferyboard.gov.au/codes-guidelines statements/professional- standards.aspx.

11. Undang-Undang Republic Indonesia Nomor 38 Tahun 2014 Tentang Keperawatan.

12. Ramadan, Amal Hamdani \& El-Demerdash SM. The Relationship between Professional Values and Clinical Decision Making among Nursing Student Amal Hamdy Abou Ramadan and Safaa Mohamed El-Demerdash. 2017;6(6):19-26. 
13. Nursing and Midwifery Board of Ireland. Based On https://www.nmbi.ie/Standards-Guidance/Code.

14. KARS. Standard Nasional Akreditasi Rumah Sakit. 1st ed. Jakarta: Komisi Akreditasi Rumah Sakit; 2017;

15. Tang, Soong, \& Lim. Patient Satisfaction with Nursing Care: A Descriptive Study Using Interaction Model of Client Health Behavior. International Journal of Nursing Science. https://doi.org/10.5923/j.nursing.20130302.04. 2013; 3 (2): 51-56.

16. Weyant \& Clukey. Show Your Stuff and Watch Your Tone: Nurses' Caring Behavior. American Journal of Critical Care. https://doi.org/10.4037/ajcc2017462. 2017; 26 (2): 111-17.

17. Robbins, Stephen \& Judge T. Organizational Behavior. 17th ed. Yagan S, editor. America: Pearson; 2017.

18. Aksoy et al. The Impact of Ethical Leadership and Leadership Effectiveness on The Mediating Role of Work. Soc Behav Sci. 2012;58:289-97.

19. Dawson AJ, Stasa H, Roche MA, Homer CSE, Duffield C. Nursing churn and turnover in Australian hospitals: nurses perceptions and suggestions for supportive strategies. BMC Nurs [Internet]. 2014;13(1):1-10. Available from: BMC Nursing.

20. Maame V, Amoah K, Anokye R, Boakye DS, Acheampong E, Budu-ainooson A, et al. A qualitative assessment of perceived barriers to effective therapeutic communication among nurses and patients. BMC Nurs. 2019;1-9.

21. Darch J, Baillie L, Gillison F. Nurses as role models in health promotion: a concept analysis. Br J Nurs. 2017;26(17).

22. Moon, et al. Nurse Education Today Evaluation of the validity and reliability of the Korean version of the Nursing Professional Values Scale-Revised. YNET. https://doi.org/10.1016/j.nedt.2013.06.014. 2014; 34(3), 325-330.

23. Cetinkaya-uslusoy E. Professional values of Turkish nurses: A descriptive study. Nurs Ethics. 2015;1-9.

24. Parandeh A, Khaghanizade M, Mohammadi E, Mokhtari Nouri J. Factors Influencing Development of Professional Values Among Nursing Students and Instructors: A Systematic Review. Glob J Health Sci [Internet]. 2014;7(2). Available from: http://www.ccsenet.org/journal/index.php/gjhs/article/view/39270

25. Schmidt BJ. Core professional nursing values of baccalaureate nursing students who are men. Nurs Ethics. 2016;23(6):674-84.

26. Watson J. Nursing: the philosophy and science of caring [Internet]. Revised. Vol. 1, Statewide Agricultural Land Use Baseline 2015. Colorado: the University Press of Colorado; $2008 . \quad 553$ p. Available from: http://site.ebrary.com/id/10347078\%5Cnhttp://books.google.com/books?hl=en\& $\mathrm{lr}=\& \mathrm{id}=3 \mathrm{Uds} 306 \mathrm{upXsC} \& \mathrm{oi}=\mathrm{fnd} \& \mathrm{pg}=\mathrm{PT} 3 \& \mathrm{dq}=$ Middle+Range + Theory+Development +Using+King+?+s+Conceptual+System\&ots=Y2b25CjTYx\&sig=tucbXGPpRxM35bFteizTagc55k\%5Cnhttp://books.google.com/books

27. Brent L, Hommel A, Maher AB, Hertz K, Meehan AJ, Santy-Tomlinson J. Nursing care of fragility fracture patients. Injury [Internet]. 2018;49(8):1409-12. Available from: https://doi.org/10.1016/j.injury.2018.06.036

28. Alligood MR. Nursing theorists and their work. 8th ed. Greenville, North Carolina: Elsevier Inc.; 2014.

29. Kim-Godwin, Y. S., Baek, H. C., \& Wynd, C. A. Factors Influencing Professionalism in Nursing Among Korean American Registered Nurses. Journal of Professional Nursing. https://doi.org/10.1016/j.profnurs.2009.12.007. 2010; 26(4), 242-249. 
30. Xiao YY, Li T, Xiao L, Wang SW, Wang SQ, Wang HX, et al. The Chinese version of Instrument of Professional Attitude for Student Nurses (IPASN): Assessment of reliability and validity. Nurse Educ Today [Internet]. 2017;49:79-83. Available from: http://dx.doi.org/10.1016/j.nedt.2016.11.013. 